\title{
Research on Rural Ecological Community Construction from the Perspective of Environmental Justice
}

\author{
Na Ning \\ College of Marxism, Sichuan Agricultural University, Chengdu, Sichuan Province, 611130, China
}

Keywords: environmental justice; rural areas; ecological community

\begin{abstract}
Environmental justice is a right that needs to be exercised freely by self-practice to enhance the ability of individuals and communities. At present, the fundamental reason for the lack of rural environmental justice in China is caused by the unreasonable sharing and distribution of environmental responsibility and ecological benefits. To solve this problem and enjoy the environmental rights on an equal footing, farmers shall be guided under the concept of green development and take the rural ecological community construction as an opportunity to fundamentally realize the sustainable development of rural areas and people's pursuit of a better life from the aspects of concept, system, industry development, lifestyle and operation mechanism.
\end{abstract}

\section{Introduction}

Environmental justice emerged as a concept in the United States in the early 1980s. It was the product of American modern civil rights movement and environmental protection. The Warren County Protest in 1982, for the first time, linked the environmental consequences with racism, poverty and industrial waste. It caused a strong reaction in the society, thus starting the environmental justice movement. In October 1991, the first meeting of the National People of Color Environmental Leadership Summit was held in Washington, where 17 principles of Environmental Justice were drafted and adopted and the different positions of "environmental justice" and mainstream environmentalists were officially declared. In October 1997, the first international conference themed on "environmental justice" was held in the University of Melbourne in Australia with a total of more than 200 scholars from 33 countries and many civil societies to participate in. What's more, the 2002 United Nations Summit on Sustainable Development took the issue of contemporary social equity as an important part of sustainable development. People of insight know to various degrees that no country or civilization can achieve sustainable development alone, unless all mankind is freed from poverty, injustice and underdevelopment. When inequality is addressed in the field of environment protection, environmental justice emerges on the stage of history.

Why some environmental problems, which have long existed, cannot attract wide attention but to a specific time? Why some environment problems have attracted wide attention while others remain silent? "Environmental problems can not materialize themselves and cannot foster problems by themselves until when they are "constructed" by individuals or organizations and are considered to be worrying and must be coped with action" [1].

Although the concept of "environmental justice" originated in the United States, the questions posed by the environmental justice movement are of universal significance. In particular, when the problem of unequal rights and obligations of environmental protection between the advantaged and disadvantaged social groups has become increasingly prominent, environmental justice wins wide response globally, especially in the less developed countries and regions. In India, the ecologist, Ramachandra Guha, published an article entitled "Radical American Environmentalism and Wilderness Preservation: A Third World Critique” in 1994, introducing the environmental problems of India and expressing their call for "environmental justice" of the poor countries and regions in their so-called "the Environmentalism of the Poor" environmental protection movement. Chinese scholar Zeng Jianping in his book "Environmental Justice: The Development of Environmental Ethics in Developing Countries", for the first time, did an exploratory and constructive study on the international environmental justice between developing countries and developed countries. Thus, it 
is clear that environmental justice issues are prevalent in many corners of the current world and as a whole with a variety of manifestations.

The so-called environmental justice refers to the right of all people to enjoy the orderly, clean and sustainable environment and free from the harm of environmental damage, regardless of their generation, race, nationality, ethnicity, culture, sex, or economic and social status. And the above-mentioned rights can be freely exercised through self-practice and the enhancement of the capabilities of individuals and communities, whereby the identity, needs and dignity of the individual and the group can be maintained, fulfilled and respected. The main purpose of environmental justice is to effectively protect people's equal environmental rights and to minimize the unequal environmental impact of people due to unequal relations. The essence of the environmental justice is the reasonable sharing and distribution of environmental responsibility and ecological benefits. Environmental justice can also help us to clearly see the social causes of ecological crisis and therefore to take the correct response strategies to solve it. Environmental justice, different from Naturalism, bases its ecological ethics on the comprehensive relationship between man and nature: to follow the laws of nature as well as the laws of society; to adjust the relationship between man and nature as well as among people. It is the value of concept based on human survival and the "sustainability" of development, the balance and unity between ecological and moral law.

In China, the social construction of environmental justice has its specific historical background and development track. In the past four decades after the "opening and reform", China's social development has been guided by the basic principles of "one center and two basic points", following the basic distribution principle of "give priority to efficiency with due consideration to fairness". These principles have greatly liberated and developed the productive forces of China, gaining sustained economic rapid development. However, with the deepening of reform, many deep-rooted contradictions gradually appeared. Ecological destruction, intertwining with the problems caused by industrialization, urbanization, employment, resource shortage, rich-poor gap and other issues with mutual interaction and restraint, finally accumulates and forms the serious social problems of China's current society. Marx once pointed out: "The relationship among things has always been an indication of the relationship among people”. In the process of rapid economic development in China, the prosperity of a small part people and regions that enrich first is gained at the expense of the environment of the other majority part of people and areas. It also leads to the environmental inequality between urban and rural areas, regions and classes and etc. The environmental inequality, vice versa, aggravates the social unfairness.

"As the environment movement gets into a new development stage, the concept of environmental justice, as a concept emphasizing the value of life, even all forms of life and against the concept of wealth, power and technology interests, is gradually winning people's heart and accounting more in the policy-making of the authorities” [2]. With the social problems caused by the environment become more and more serious, the environmental justice in China is attracting more and more attention. However, since environmental justice is often obscured by the general environmental issues, under the long-term guiding ideology "Development is of overriding importance", people often mistakenly or deliberately believe that the concept of environmental justice will force the underdeveloped groups or underdeveloped regions to make choice between economic development and environmental protection. In general, the upper class, relying on their strong social resources, can avoid and transfer risks while accumulating social wealth so that the risk will concentrate on the lower class. The poor always bear a lot of risk. So is the environmental pollution. In China, the risk will no doubt falls on the head of the farmers. [3] The ecological environment risk in China has been accumulated in the rural areas for a long time and has not been effectively released and dealt with. Farmers are often in the dilemma to make choice between "survival" and "protecting environment". It is not uncommon that farmers take the initiative to give up their environmental rights for material compensation. The environmental justice between urban and rural areas has become an unavoidable theoretical and realistic problem in the current governance of rural environment. 


\section{The Lack of Environmental Justice between the Rural and Urban Areas}

As a large agricultural country, rural areas are the largest areas of social and economic development in China. As the rural ecological environment and natural resources are often the most basic livelihood for farmers in their production and life, farmers naturally rely more closely on rural natural resources. Therefore, the state of rural ecological environment, the realization of environmental justice between the rural and urban areas, farmers and urban residents, and the farmers' rights on environment and development, relate not only to the realization of environmental justice but also the efficiency of agriculture production as well as the sustainability of the farmers' production and life.

In terms of the economic environment, China's per capita net income of rural residents is less than half of the per capita disposable income of urban residents (Table 1), in the absolute less advantaged position. In terms of the natural environment, China's 600 million agricultural population share 1.35 million square kilometers of arable land (2015), less than half of the world average per capita arable land area. China is in a shortage of arable land resources and the contradictions between people and arable land is quite prominent. The state of water resources is even worse, with per capita ownership of water about $2039.2 \mathrm{~m} 3$ (2015), only about one-fourth of the world average. In terms of ecological environment, due to the long-term improper or overdevelopment and utilization, the rural ecosystem has been severely damaged with degradation in forests, grasslands, lakes, farmland and other ecosystem and the gradual deterioration in biodiversity. Natural disasters happen more frequently in recent years with more and more serious consequences. Environmental pollution is mainly manifested by the pollution caused by the improper use of farmers of the chemical fertilizers, pesticides, plastic film, livestock and poultry manure, garbage etc. in the process of agricultural modernization and intensification, by the "industrial waste" pollution released by township enterprises, urban industries and urban and rural life and the "external pollution" of noise and garbage transferred from urban areas and the pollution of surface water, underground water and soil pollution resulting from these garbage transference. Some urban suburbs have become the "reservoir" of municipal waste and sewage, and it is obvious that this trend is spreading to more remote areas.

Table 1: Per Capita Income of Urban and Rural Residents

\begin{tabular}{|c|c|c|c|c|}
\hline \multirow{2}{*}{ Year } & \multicolumn{2}{|c|}{$\begin{array}{c}\text { per capita disposable income of } \\
\text { urban residents }\end{array}$} & \multicolumn{2}{c|}{$\begin{array}{c}\text { per capita net income of rural } \\
\text { residents }\end{array}$} \\
\cline { 2 - 5 } & $\begin{array}{c}\text { Number } \\
\text { (Yuan) }\end{array}$ & $\begin{array}{c}\text { Index } \\
(1978=100)\end{array}$ & $\begin{array}{c}\text { Number } \\
\text { (Yuan) }\end{array}$ & $\begin{array}{c}\text { Index } \\
(1978=100)\end{array}$ \\
\hline 2011 & 21809.8 & 1046.3 & 6977.3 & 1063.2 \\
\hline 2012 & 24564.7 & 1146.7 & 7916.6 & 1176.9 \\
\hline 2013 & 26955.1 & 1227.0 & 8895.9 & 1286.4 \\
\hline 2014 & 29381.0 & 1310.5 & 9892.0 & 1404.7 \\
\hline 2015 & 31790.3 & 1396.9 & 10772.0 & 1510.1 \\
\hline
\end{tabular}

* Source: China Statistical Yearbook 2016

This intra-generational environment injustice in the rural areas is not only caused by the urban-rural dual structure. "The environmental problems are actually caused by the injustice of social relations and social structures, so the key to solve them is to focus on the rebuilding of social justice by coordinating social relations and adjusting social structures." [4] The current urban and rural environment injustice can be manifested as the injustice of natural environment and the injustice of social environment. The former refers to the natural injustice between urban and rural areas in terms of their natural environmental resources. Compared with the city, the rural areas are endowed with rich natural resources but with no enough value recognition, which directly leads to the construction of rural environment more difficult than the city. The latter refers to the fact that in handling the environmental affairs, the city has a more favorable economic and social condition than the rural areas to deal with the environmental crisis. For a long time, Chinese government has been focusing more and investing more on industrial and urban pollution control in its 
environmental protection effort (Table 2). The improvement of urban environment is often at the expense of the rural environment, and the rural areas have not received their corresponding ecological compensation. At the same time, the relevant policies and regulations on protecting rural environment are not well-developed. What's more, since farmers are at a more disadvantage position compared with urban residents in their environmental awareness, information access, the involvement of environmental affairs and other aspects, their awareness on environmental protection and the ability to fight for their environment are quite limited. The problem of environmental justice is becoming more and more prominent in rural areas, which is seriously threatening their environmental security and sustainable development and becoming a bottleneck that restrains the construction of new countryside.

Table 2: Investment in Environmental Pollution Control

\begin{tabular}{|c|c|c|c|c|c|}
\hline Year & 2011 & 2012 & 2013 & 2014 & 2015 \\
\hline $\begin{array}{c}\text { Total investment in } \\
\text { environmental pollution } \\
\text { control (100 million yuan) }\end{array}$ & 7114.0 & 8253.5 & 9037.2 & 9575.5 & 8806.3 \\
\hline $\begin{array}{c}\text { Investment in urban } \\
\text { environmental infrastructure } \\
\text { construction }\end{array}$ & 4557.2 & 5062.7 & 5223.0 & 5463.9 & 4946.8 \\
\hline Gas & 444.1 & 551.8 & 607.9 & 574.0 & 463.1 \\
\hline Centralized heating & 593.3 & 798.1 & 819.5 & 763.0 & 687.8 \\
\hline Drainage system & 971.6 & 934.1 & 1055.0 & 1196.1 & 1248.5 \\
\hline Landscaping & 1991.9 & 2380.0 & 2234.9 & 2338.5 & 2075.4 \\
\hline Environmental sanitation & 556.2 & 398.6 & 505.7 & 592.2 & 472.0 \\
\hline $\begin{array}{l}\text { Industrial pollution control } \\
\text { investment }\end{array}$ & 444.4 & 500.5 & 849.7 & 997.7 & 773.7 \\
\hline $\begin{array}{l}\text { Environmental investment on } \\
\text { completed environmental } \\
\text { protection project of that year }\end{array}$ & 2112.4 & 2690.4 & 2964.5 & 3113.9 & 3085.8 \\
\hline $\begin{array}{l}\text { The proportion of investment } \\
\text { on environmental pollution } \\
\text { control to total gross domestic } \\
\text { product (\%) }\end{array}$ & 1.45 & 1.53 & 1.52 & 1.49 & 1.28 \\
\hline
\end{tabular}

* Source: China Statistical Yearbook 2016

From the perspective of environmental justice, the current environmental problems in rural areas not only reflect the imbalance between human and nature, but also the imbalance of social relations among people, an extension of social problems. Therefore, if we do not link the rural environmental problems with the realization of social equity, and if the fair social environment cannot be guaranteed, the deterioration of the rural ecological environment will be difficult to be curbed effectively and the rural environmental crisis will not be effectively tackled. If we only emphasize one-sidedly on the economic performance of the construction of new countryside, on the construction of its hardware such as the road, water conservancy, housing and other facilities related to production and living, and ignore the protection and improvement of rural ecological environment, it is hard for us to realize the goal to build a new socialist countryside.

\section{The Construction of Ecological Community is the Inevitable Choice to Achieve Sustainable Development in Rural Areas}

Since the reform and opening up, China's rural areas have undergone tremendous changes. The agricultural economy develops continuously and hundreds of millions of farmers in general get out of poverty. Rural areas are gradually getting urbanization and the traditional rural economic and social development are experiencing historic transformation and remodeling under the impact of 
industrialization and urbanization. However, today's rural areas in China are still facing enormous challenges and problems. Agriculture is facing a series of problems such as high input, low output, low efficiency, high consumption and overuse of resources, ecological deterioration, environmental degradation and poor rural living conditions. The excessive pursuit of economic production pushes the traditional ecological agriculture system to the brink of collapsing. To achieve the efficient and sustainable use of agricultural resources and the fundamental improvement of the living environment of farmers, copying the old road of urban development is not a feasible way. We must change the mode of rural development and agricultural production. Therefore, the development of new modern agriculture, green ecological agriculture, scientific and efficient agriculture has become the only choice for the development of new agriculture and the construction of rural ecological communities has correspondingly become the inevitable choice to achieve the sustainable development in rural areas.

In fact, the human villages have existed for thousands of years. They have always been the "carrier of agricultural production", "the roots of human emotion", "the living fossils of cultural heritage", "the mirror of urban development", and "the link between people and nature". They exist for many deep-rooted reasons. In essence, the countryside was originally an ecological system for settlement and of great ecological importance. "The villages are consisted mainly by rural population with the companion organisms as their main biological community and the facilities constructed for the habitat as the important artificial ecosystem. It is the combination of agroecosystem and human ecosystem system, an important sub-system of agroecosystem”. [5] It is the realistic need for the development of rural modernization to carry out the rural ecological community construction in the rapid development process of industrialization and urbanization. It is also the modern reconstruction of rural traditional ecological civilization and the sublimation of our value. It is the fundamental way to balance urban and rural environmental justice as well as a major guarantee for the healthy and sustainable development of cities and the second and third industries. Therefore, we should notice the important value of the construction of modern countryside in the maintenance of ecological security, and strive to retain the "root" of rural ecology and rural culture.

The construction of rural ecological community is a new model of community development under the guidance of green development concept. In foreign countries, the rural ecological community was first put forward by the Danish scholar Robert Gilman with the concept of "ecological village" [6]. He pointed out that the ecological villages were based on human activities which should be limited to the extent that would not damage the environmental characteristics of their natural residence. It supported the healthy development and utilization of resources to guarantee its sustainable development until to the unknown future. Australian scholar Robert J.S. Beeton further summarized the "rural ecological community" as a community development model based on the interdependence between man and nature, the conversion of capital in various forms, the improvement of environmental management and the sustainable development of rural ecological environment. [7] In China, the concept of ecological community has also attracted the attention of many scholars. Chen Weizhen and other scholars pointed out that the rural ecological community was based on the natural ecology with the rural population as the main living population and villages as the specific communities. It is an ecological and human economic and social system decorated with ecological and cultural landscape. [8] Yang Bin, etc. put forward the rural ecological community, was a new rural development model based on the ecological perspective to build an ecological civilization of sustainable development and a new harmonious socialist well-off society. [9]

To sum up, the rural ecological community should have the following characteristics: first, it emphasizes the "people-oriented and the harmonious coexistence between man and nature" ecological civilization concept. It is a kind of ecological concept based on practice, which means the construction of the community should be people-oriented and the harmony between man and nature should be realized; second, it is a concept of sustainable development. We should guide farmers to optimize the ecological environment, to develop ecological economy, to construct ecological culture and to build their beautiful home. The ecological community should not only 
reflect the concept of ecology but also the new ideas of sustainable development; third, it should emphasize on the concept of constructing a "harmonious" society, which involves not only the harmony between farmers and nature but also the harmony among people and different systems in the rural community. On the whole, the rural ecological community should adhere to the people-oriented principle and mobilize the major force of the community to optimize the community ecological environment, build community ecological culture, and gain sustainable development by establishing an environment-friendly, resource-conservation-minded economy of sustainable development to realize the harmony coexistence between man and nature and form a new model of community development in a harmonious rural society. The construction of rural ecological community is of great significance to promote the modern rural social civilization since it is a sustainable and healthy development. It can guide the practice of rural social management and solve the problem of rural environmental justice. It is also an innovation of the contemporary social development concept.

\section{Fundamental Ideas for the Construction of Rural Ecological community}

The construction of rural ecological community of sustainable development is the direction for future rural community construction and development. The solving of rural environment injustice should base on the basic principles that are people-oriented and focus on the harmonious coexistence between man and nature and sustainable development. It mainly includes the following ideas.

The construction of rural ecological communities believes that community members are both owners and users of community resources, which offers them the advantage that others do not have. Therefore, farmers' participation in community ecological environment governance is both necessary and effective. As a member of the rural community, farmers are not only the main body of rural ecological community construction and the ultimate beneficiaries but also the key to ecological community construction. Consciousness can actively transform human behavior. Only after farmers have ecological awareness and frugal consciousness can they take the initiative to build green, ecological rural communities under the concept of green development. "We should embody the concept of ecological civilization in concrete forms to make it popular by compiling books on ecological civilization for community residents to comprehensively explain and analysis the requirements of ecological civilization construction". [10] We also can give lectures on ecological knowledge so that farmers can know more scientific knowledge on green ecology. The awareness improvement of green ecology of the community members should be addressed first from the practice of vital interests in farmers' daily life. At the same time, we should pay attention to the construction of spiritual civilization in the community to strengthen their ecological awareness and participation consciousness by organizing a variety of activities that are loved by the majority of farmers such as knowledge contest and art shows to make the ecological concepts and knowledge become a part of their daily life, and to enhance their ecological awareness unconsciously, so that the ecological concept can be transformed as their daily behaviors in the daily life and production. With their increased ecological awareness, farmers are expected to participate more in the construction of green community.

The construction of rural ecological community is an organic system, in which the construction of rural community ecological civilization is one of the important contents. The construction of ecological civilization requires the participation of all parties. Therefore, we need to take all the parties in rural community into consideration including the government, the factories and enterprises that produce pollution, breeding bases, farmers and other social forces in building the protection mechanism of community ecological civilization. In recent years, the development of rural communities is directly linked to the assessment of local government, but the drawbacks of this assessment method which emphasize more on economic development than environmental protection are gradually appearing. Generally speaking, the new ecological protection mechanism of rural communities should increase the proportion of environmental protection in assessing the government performance with the implementation of dynamic evaluation and accountability 
mechanism. And the punishment mechanism should be strengthened in the actual practice and severe measures such as huge fines, production suspension, and criminal penalties can be taken to punish the factories, enterprises, breeding bases which pollute the environment of rural communities so that they cannot and dare not discharge pollutants. Rural communities are the land of existence for farmers, and therefore, we should fully exert the role of farmers, strengthen their role in supervision, and actively guide them to participate in the environmental protection by forming an effective rewarded-reporting mechanism. Since the operation of the system relies closely on the support of laws, we need to strengthen the development of laws and regulations systems on rural ecological and environmental protection construction and give full play to the role the newly revised "Environmental Protection Law" in maintaining the construction of rural ecological civilization.

Currently, in face of the serious rural environmental pollution, the construction of a large-scale eco-industrial system which includes multiple recycling, efficient and sustainable industries such as the ecological agriculture, ecological industry and ecological service to rapidly develop the rural economy and to gradually change farmers' way of production and life is an important way to promote the transformation and development of rural areas and protect the rural ecological environment. In practice, we can learn from the strategies of Japan's "Rural Building Movement", and adhere to the principle that develops the industry of unique features in line with the different characteristics of local resources. We can carry out the "one -village- one -product" development plan according to the difference in agriculture, industry, and business among villages. [11] The rural land circulation should be conducted in line with the existing policy and respect the wishes of farmers, vigorously developing a variety of ecological agriculture according to local conditions. For example, in rural areas where there are plains and large areas of hills and low mountains, farms should develop breeding industry and plant fruit trees; in the multi-mountainous areas, farmers can adopt the "four-in-one" ecological agriculture development model which combines the development of biogas digesters, pig breeding, greenhouses vegetation, and the production of fruits, vegetables and other agricultural products; in the plain area, we can plant crops intermittently with economical plants such as melons, fruits, and vegetables and develop agroforestry .[13] In the industrial development, we must follow the universal and objective principle of ecological development, adhere to the concept of circular economy, change the traditional industrial model that is of high pollution and high consumption of energy and take use of the regional clean energy to develop the recycling, efficient and ecological industries, and form a green eco-economic development model. At the same time, we also need to fully exert our initiative actively and vigorously develop the flowery industry, fruit and vegetable picking industry, and agriculture tourism that is both leisure and ecological according to the characteristics and natural endowment of different regions, and develop ecological service industry that involves tourism, leisure, and services. Through the development of ecological agriculture, ecological industry and ecological service, we can replace the unsustainable traditional agriculture which brings single and low income with a great waste of resources and workshop processing industry of high pollution with a recycling, efficient and sustainable eco-industrial system.

The construction of rural ecological communities based on the green development concept is a social construction movement involving profound changes in production methods, lifestyles, ways of thinking and values. It will change the way of life of the whole society and be of great significance for the conservation of resources, the protection of environment, and the realization of harmony between man and nature. In this new historical period, it has become an important part of building an ecological community to change the former extravagant and wasteful consumption concept of the community people which pay too much attention to seeking comforts and pleasures of life, form the new green consumption concept and carry out the green consumption lifestyle. First of all, we need to start from the ideological education and educate the people in the community with "green" ideology, spread the low-carbon, frugal, and green consumption ideas so that the community people can pursue a green low-carbon lifestyle with their actual action. Second, through popularizing the knowledge related to green lifestyle, propagandizing the good traditional culture of 
frugality and organizing public activities on green consumption, we can make the community people fully understand the green consumption ideas and transform these ideas into their conscious behaviors so that green and low-carbon consumption can become a part of their daily life. At the same time, we can educate the community people with the things surrounded them and typical cases. Through the promotion, guidance, demonstration, and public participation, we are committed to change the low-carbon, green, and frugal consumption culture into a trend so that it can become part of the community culture, the norms of their daily behaviors, and lay the foundation of the ecological communities.

In recent years, the rural community mechanisms have exposed many drawbacks in their operation such as no specific governor, focusing too much on interest, deviating from the public opinion and reality, enjoying power without accountability etc. Therefore, it is urgent to find a reasonable model of community development to solve these problems. We need to construct a scientific, rational and innovative community management model, giving full consideration to the various realistic factors of the community and starting from the optimization of mechanism operation. Community residents are the main undertakers in the construction of ecological community and the direct beneficiaries. So, we need to clear their responsibility as the main body of the community, and actively guide them to participate in the construction of their own ecological homes. In addition, the township governments hold unshakable responsibility in the construction of rural ecological community. The governments should raise their support for the construction of rural ecological community, specify the division of responsibility and obligation between different functional departments, and establish a linkage mechanism based on the consistence of power and responsibility. The governments also need to strengthen their effort in the adjustment of rural industries and the supervision and guidance for industrial development so that they can have an effective monitor on the rural ecological environment. For individuals, grass-roots cadres, enterprises that violate the rules and laws of environmental protection and destruct the ecosystem, the governments should punish them with severe penalties. The governments also need to exert their function in coordination, management and monitoring and make beneficial interaction with other subjects. In addition, we should improve laws and regulations on the rural ecological and environmental protection, so that the ecological construction of rural communities can be conducted in according to the law. In short, it is an important path of the current ecological community construction to form a people-oriented community ecological management model with participation of multi-subjects including farmers, government and community organizations based on the consistent principle of right and duties in the reality.

\section{Conclusion}

Environmental justice, as a concept based on the survival and "sustainable" development of human beings, points out the direction for studying the deep social reasons behind the current problems in China's rural areas such as the decreasing of natural resources, ecological destruction, environmental pollution etc. The principles of environmental justice believe not only that people should eliminate their damage to the environment but also that the basic right of survival and self-determination of everybody should be guaranteed by environmental protection. This paper analyzes the present situation of urban and rural income and environment in China, and reveals the fact that the rural areas in China have become the carriers of pollution and environmental victims of China's rapid economic and social development. The lack of urban and rural environmental justice, fundamentally speaking, is caused by the injustice between social relations and structures, which further aggravates this injustice and ultimately affects the healthy development of the entire national economy and society seriously. The author, in this paper, takes the opportunity that China is constructing rural ecological communities in large scale, explores the feasible way to construct rural ecological communities from aspects on how to cultivate the ecological consciousness of the farmers, how to construct the environmental protection mechanism, how to build the ecological industry system, how to form a low-carbon lifestyle and how to establish the ecological management mode of the community so that the living environment of farmers can be improved 
with the fundamental change in the overall system and the problem of urban and rural environment injustice can be successfully addressed with the reconstruction of social relations and the strengthening of the farmers' autonomy. This is a revolutionary change in China's rural history and a major exploration of building a new socialist countryside under the new situation.

\section{References}

[1] Hong Dayong. On Environment Issues and Relevant Sociological Interpretation Patterns. Journal of Renmin University of China. 2002(5). P58-62.

[2] Manuel Castells. The power of identity. The information age: economy, society, and culture. 2010.

[3] Wang Jingge. The Protection of Peasants' Environment Right. Journal of Henan University (Social Science). Vol.57, No.3. May, 2017. P56-62.

[4] Li Peichao, The Basic Connotation of "Intrageneration Justice” in Environmental Ethics. Studies in Ethics, 2002(9). P51-54.

[5] Wang Zhiping, Ecological distribution characteristics of village system in different regions. Chinese Journal of Applied Ecology. Oct. 1993,4(4). P374-380.

[6] Robert Gilman.The Eco-village Challenge. In Context, 1991 (29).

[7] Robert J. S. Beeton, A. Jasmyn J. Lynch. Most of nature: A framework to resolve the twin dilemmas of the decline of nature and rural communities. Environmental Science\&Policy, 2012(23). P45-56.

[8] Chen Weizhen, Yang Xuejun. Thoughts Over New Style Eco Rural Community Development in Chenjia Town of Chongming. City Planning Review. Vol.32, No.8. AUG. 2008. P31-35.

[9] Yang Bin, Shi Longyu, Li Chunming.The concept and evaluation indicator system of rural ecological community. Environmental Science \& Technology. 2015,38 (12Q). P419-423.

[10] Ma Mingchong, Zhao Meiling, Research on Green Ecological Governance from Perspective of Sustainable Development. Ecological Economy, 2014(7). P175-178.

[11] Ximing Wang, International experience in the construction of beautiful countryside. Changbai Journal. No. 5, 2014. P106-113.

[12] Cao Junjie, Analysis on the Features and Efficiency of Several Modern Eco-agriculture Models in Shandong Province, China Soft Science, 2010(12). P107-114. 